\title{
Synthesis of highly dispersed palladium alumina supported particles: Influence of the particle surface density on physico-chemical properties
}

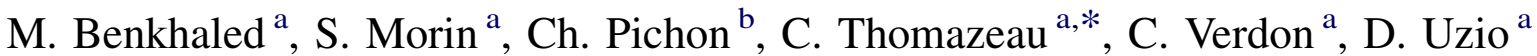

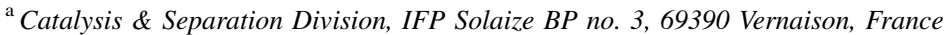 \\ ${ }^{\mathrm{b}}$ Physics and Analysis Division, IFP Solaize BP no. 3, 69390 Vernaison, France
}

Received 29 March 2006; received in revised form 16 May 2006; accepted 2 June 2006

Available online 7 August 2006

\begin{abstract}
Complexation with nitrite ions in aqueous medium was used to prepare highly dispersed $\mathrm{Pd}^{\circ}$ particles supported on alumina. It has been possible to obtain catalysts with different Pd loading keeping the particle size lower than $1 \mathrm{~nm}$ as shown by HRTEM, chemisorption, or extended X-ray absorption fine structure (EXAFS) characterizations, and as a consequence with different particle surface density. We observed that electronic properties measured by IR(CO) or X-ray photoelectron spectroscopy (XPS) measurements are strongly influenced by this last parameter and that the origin of these variations can be related to the different strengths of the interactions of the palladium precursor with the alumina surface sites as shown by low temperature CO adsorption followed by FTIR spectroscopy. On increasing Pd loading, saturation of unsaturated Lewis surface sites follows their acid strength: the more acidic ones are the first to react as germination sites, followed by the medium and finally the weaker sites. These different interactions may explain the variation of electronic properties of such small reduced particles which appears to be very sensitive to the chemical nature of their initial germination site on the oxide support. On the other hand, no such effects were observed on changing the type of alumina $(\delta$ or $\gamma$ ) support, in agreement with the principle of the synthesis method which tends to limit strong interaction with the support. Comparison with $\mathrm{Pd}^{\circ}$ particles with the same particle size and particle surface density but prepared with the well known grafting of acetylacetonate precursor shows marked differences in terms of electronic properties followed by CO FTIR. This result illustrates the possibility to prepare highly dispersed Pd particles with different physico-chemical properties.
\end{abstract}

(C) 2006 Published by Elsevier B.V.

Keywords: Palladium; Heterogeneous catalyst preparation; Nano particles; Alumina; Particle surface density

\section{Introduction}

Various methods for the preparation of small supported metallic particles have been proposed in the literature. Because of the unstable thermodynamic state of highly dispersed particles, the basis of most of preparation methods consists in a strong stabilization of the metallic particles on the oxide support in order to prevent sintering during catalytic applications or regeneration steps. Since the pioneering works of Yermakov [1,2] organometallic precursors (metallocene CPD, COD, carbonyl), alkoxides like acetylacetonate or ethoxy, have been successfully applied for the synthesis of very small particles of various type of metals deposited on silica or alumina [3-10].

\footnotetext{
* Corresponding author. Tel.: +334 780229 04; fax: +334 78022066 . E-mail address: cecile.thomazeau@ifp.fr (C. Thomazeau).
}

Interaction with hydroxyl or coordinately unsaturated sites (CUS) of the oxidic carrier leads to grafted metallic species and, after appropriate thermal treatments, to highly dispersed particles [11-13].

In the aqueous phase, electrostatic, hydrolytic adsorption or ionic exchange are also well documented techniques for the preparation of highly dispersed metallic phase on an oxidic carrier [14-16]. Interactions between the precursor and the support may be created during the impregnation step or thermal post-treatments by exchange of the ligand with hydroxyl groups of the support and progressive formation of oxide particles. Operating conditions such as $\mathrm{pH}$ of the solution, duration of impregnation, atmosphere of thermal treatment, are parameters controlling the final dispersion of the particles $[17,18]$.

These interactions play a key role in the final properties of the metallic active sites, controlling morphology, electronic properties and finally overall catalytic performances [19-21]. 
Usually, results in literature report a decrease of the metallic character of the atoms for small particles with an "electron deficient" character as initially proposed by Boudart and coworkers $[22,23]$ and then demonstrated in theoretical and experimental studies [24-30]. As a consequence, the catalytic activity will be perturbed by the changes in adsorption strength and consequently in surface coverage or adsorption mode of reactants and products. Several works shows some remarkable physico-chemical properties or catalytic behavior of very small supported clusters. In particular, even if these properties reach the asymptotic values corresponding to the bulk when the particle contains about 20 atoms, non monotonous variations are found with progressively increasing number of atoms [31]. Activity for various reactions seems to be sensitive to the exact number of atoms [32,33]. These discontinuities are thus potentially interesting to explore in catalysis [34-36].

In this paper, we present a preparation method which allows us to produce very small Pd supported particles with a tunable metal-support interaction. The principle of this method, quite different compared to usual strategies, consists in avoiding strong interactions with the support at the different steps of the synthesis: in solution between ionic metallic precursor and the surface of the support and during the following activation steps to transform molecular complexes into small supported metallic particles.

\section{Experimental}

\subsection{Catalysts preparation}

The preparation method used an aqueous solution of palladium nitrate (Heraüs) and a defined quantity of $\mathrm{NaNO}_{2}$ (Aldrich 99.99\%), corresponding to a molar ratio $\mathrm{NO}_{2} /$ $\mathrm{Pd}=4$. Incipient wetness impregnations were realized in a rotating beaker. After drying at $393 \mathrm{~K}$, the catalyst was calcined under airflow at $473 \mathrm{~K}$ during $2 \mathrm{~h}$ and finally reduced under hydrogen flow. In order to remove residual $\mathrm{Na}$, a washing step with water was performed. FTIR and thermogravimetric analysis of $\mathrm{Pd}\left[\mathrm{NO}_{2}\right]$ catalysts were performed on samples before the washing step. These catalysts are here referred as $\mathrm{Pd}\left[\mathrm{NO}_{2}\right]_{\mathrm{nw}}$ (as "not washed" samples). The palladium loading was varied from 0.1 to 0.6 wt. $\%$ and two types of alumina support were used: a $\delta-\mathrm{Al}_{2} \mathrm{O}_{3}$ (specific surface area $S_{\mathrm{BET}}=130 \mathrm{~m}^{2} / \mathrm{g}$ and porous volume $\left.V_{\mathrm{p}}=1.04 \mathrm{cc} / \mathrm{g}\right)$, and a $\gamma_{\mathrm{c}}-\mathrm{Al}_{2} \mathrm{O}_{3} \quad\left(S_{\mathrm{BET}}=200 \mathrm{~m}^{2} / \mathrm{g}, \quad V \mathrm{p}=\right.$ $0.6 \mathrm{~cm}^{3} / \mathrm{g}$ ). These catalysts are labeled here as 130 or $200 \mathrm{Pdx}(1<x<5)$. In order to make a comparison, two others catalysts have been prepared starting from bisacetylacetonate (Strem 99\%) in organic medium. The desired amount of $\operatorname{Pd}\left(\mathrm{C}_{5} \mathrm{H}_{7} \mathrm{O}_{2}\right)_{2}$ is dissolved in $300 \mathrm{ml}$ of toluene and added to $20 \mathrm{~g}$ of $\delta-\mathrm{Al}_{2} \mathrm{O}_{3}$ (referred as 130Pd[acac]) or $\gamma$ $\mathrm{Al}_{2} \mathrm{O}_{3}$ (200Pd[acac]) for $72 \mathrm{~h}$ at room temperature under stirring. The mixture is then filtered and washed 3 times with $100 \mathrm{ml}$ of distilled water. After drying at $393 \mathrm{~K}$ during $12 \mathrm{~h}$, the catalyst is finally calcined in an air flow at $623 \mathrm{~K}$ during $2 \mathrm{~h}$.

\subsection{Characterization techniques}

The initial aqueous solutions were characterized by UV-vis spectrophotometry using a Perkin-Elmer Lambda 11 spectrometer. Spectra are recorded in the 200-700 nm wavelength range.

CO chemisorption was performed using a dynamic method: several pulses of a precise volume of $\mathrm{CO}$ were injected into the reactor until no further consumption was observed by gas chromatography. Samples were previously reduced under hydrogen flow at temperatures selected on the basis of TPR results. Adsorbate/Pd stoechiometry was determined from IR(CO) result taking into account the linear and bridged species proportions. Assuming a spherical shape of the particles (sphere), a determination of the mean particle size (surface equivalent) and dispersion can be easily obtained [37].

Thermogravimetric analysis experiments have been carried out in a Setaram thermogravimetric analyser (model TGA TAG24-12S, symetric), with a sample mass of about $100 \mathrm{mg}$, placed in a quartz crucible. This apparatus is connected to a Balzer mass spectrometer (Thermostar model) via a heating line to prevent any condensation. All masses up to 200 can be detected. The total gas flow rate is controlled by flow meters and fixed at $2 \mathrm{Nl} / \mathrm{h}$. Once the sample is introduced in the crucible, the balance is closed and a purge of the residual air $\left(\mathrm{O}_{2}, \mathrm{~N}_{2}\right.$ and water traces) within the apparatus is carried out at ambient temperature during about $24 \mathrm{~h}$. Helium or Argon are used for this purpose. The masses corresponding to $\mathrm{N}_{2}$ and $\mathrm{O}_{2}$ are recorded during this initial step, the experiment effectively starts after complete removal of these signals.

Depending on the experiments or sample, one or two intermediate steps at a temperature of 393 or $473 \mathrm{~K}$ during several hours are performed. At the end of each experiment, a final thermodesorption step, under $\mathrm{He}$ at $2 \mathrm{Nl} / \mathrm{h}$, up to $1073 \mathrm{~K}$ with a heating ramp of $5 \% \mathrm{~min}$ is carried out. Temperature and sample mass are continuously recorded during the experiment. All the gases are of analytical grades and pass before each experiment through gas filters (activated carbon and 5A zeolite) to remove possible traces of water or other contaminants.

Scanning transmission electronic microscopy (STEM) was carried out on a FEI Tecnai 20FUT at $200 \mathrm{kV}$. Particle observations were performed after reduction at $473 \mathrm{~K}$ (for $\mathrm{Pd}\left[\mathrm{NO}_{2}\right]$ ) or $723 \mathrm{~K}$ (for $\mathrm{Pd}[\mathrm{acac}]$ ) under $\mathrm{H}_{2}$ flow. The $\mathrm{Pd}$ catalysts were crushed in ethanol and deposited on a perforated carbon film supported by a $\mathrm{Cu}$ grid. In order to optimize the detection of the small particles, observations in dark field mode (HAADF) were carried out using the contrast due to the high difference of atomic number between Pd and elements of the support.

Extended X-ray absorption fine structure (EXAFS) experiments were carried out in the Laboratoire pour l'Utilisation de Rayonnement Electromagnétique (Orsay) at the EXAFSIV beam line using synchrotron radiation from the DCI storage ring running at $1.85 \mathrm{GeV}$ with an average current of $250 \mathrm{~mA}$. $\mathrm{X}$-ray absorption spectra were obtained in the transmission mode through a double crystal monochromator [Si(3 11$)$ ] using two ion chambers as detectors. The EXAFS unit equipped 
with a heater, water cooling system, thermocouples and a system of gas circulation allows in situ treatment of samples at temperatures up to $773 \mathrm{~K}$. The apparatus is identical to that designed by Lytle [38]. The $\mathrm{Pd}\left[\mathrm{NO}_{2}\right]$ samples were reduced in situ under pure hydrogen using a temperature ramp (298$473 \mathrm{~K}, 5 \mathrm{~K} / \mathrm{min}$ ) followed by a plateau of $20 \mathrm{~min}$ every $50 \mathrm{~K}$ and at $473 \mathrm{~K}$. Total reduction time was $205 \mathrm{~min}$. Edge spectra (in XANES the region from 24,250 to $24,500 \mathrm{eV}$ ) were obtained at $50 \mathrm{~K}$ intervals during reduction. After reduction the specimens were cooled to room temperature and full $\mathrm{X}$ ray absorption spectra (in the region between 24,250 and $25,150 \mathrm{eV}$ ) were acquired with an acquisition time of about $1 \mathrm{~h}$. Normalized EXAFS spectra were isolated from the experimental data using a standard procedure $[39,40]$.

Fourier transforms (FT) of the $k^{3}$ weighted EXAFS functions were obtained using a Kaiser type window ranging between 2.8 and $12.70 \AA^{-1}$ beyond the Pd K-edge (the spectra are noisy above this limit). In this work, all FT were calculated and are presented without a phase correction.

The maximum absorption coefficient of the specimen (at around 24,370 eV) compared to that of Pd metal was used as an indication of Pd reduction. The EXAFS spectrum for one or several co-ordination shells was isolated by inverse Fourier transform of the radial distribution function (RDF) over the appropriate region and fitted using the single scattering EXAFS equation. Amplitude and phase functions for fitting $\mathrm{Pd}-\mathrm{O}$ and $\mathrm{Pd}-\mathrm{Pd}$ shells were obtained respectively from $\mathrm{PdO}$ powder and $\mathrm{Pd}$ metallic foil.

X-ray photoelectron spectroscopy (XPS) measurements were performed with a VG Escalab 220 spectrometer using $\mathrm{Al}$ $\mathrm{K} \alpha$ radiation at $1486.6 \mathrm{eV}$. The pass energy of electrons was $50 \mathrm{eV}$ with a triple Channeltron analyser. The vacuum inside the analysis chamber was less than $10^{-9}$ Torr and accuracy was $\pm 0.1 \mathrm{eV}$. Samples were analyzed before or after reduction at $473 \mathrm{~K}, 2 \mathrm{~h}$ for $\mathrm{Pd}\left[\mathrm{NO}_{2}\right]$ or $623 \mathrm{~K}$ for $\mathrm{Pd}[\mathrm{acac}]$ series, and taking the $\mathrm{Al} 2 \mathrm{p}$ core level at $74.6 \mathrm{eV}$ for calibration. Photopeak deconvolutions are obtained using Gaussian-type curves.

Castaing $\mu$ probe analysis was performed to determine the radial profile of $\mathrm{Pd}$ concentration along the diameter of the alumina beads. The preparation of the measurement includes an embedding in a metacrylate resin, polishing with $\mathrm{SiC}$ paper and coating with carbon black. Measurements were performed with a JEOL JXA 8800R microprobe fitted with four WDS spectrometers. Electron beam conditions were $20 \mathrm{kV}$ accelerating voltage, $40 \mathrm{nA}$ beam current and a focused probe. The $\mathrm{Al} \mathrm{K} \alpha$, and $\mathrm{Pd} \mathrm{L} \alpha$ lines were acquired using respectively TAP, and PETH crystals. Counting times on both peak and background were respectively 10 , and $20 \mathrm{~s}$. Elemental quantification was performed using a ZAF procedure, oxygen being calculated by stoechiometry $\left(\mathrm{Al}_{2} \mathrm{O}_{3}\right)$. About 24 analysis points were acquired each $50 \mu \mathrm{m}$ along the diameter on five different samplings.

FTIR spectra of probe $\mathrm{CO}$ molecule were obtained on a Nicolet Nexus Fourier transform instrument. Catalyst samples (about $10 \mathrm{mg} / \mathrm{cm}^{2}$ ) were pressed under about $200 \mathrm{~kg} / \mathrm{cm}^{2}$ into self-supporting disks (16 $\mathrm{mm}$ in diameter) and loaded in the in situ IR cell. The catalyst first undergoes a thermal cleaning treatment at $473 \mathrm{~K}$ for $16 \mathrm{~h}$ under secondary vacuum (about $10^{-6}$ mbar). It is then reduced under $400 \mathrm{mbar}_{2}$ at $623 \mathrm{~K}$ for $2 \mathrm{~h}$. After desorption and cooling to $303 \mathrm{~K}$ under secondary vacuum $\left(10^{-6}\right.$ mbar $)$, pulses of $\mathrm{CO}(1 \%$ in $\mathrm{Ar})$ are introduced until saturation.

All results reported herein are difference spectra, corresponding to the IR spectra of the samples plus adsorbed $\mathrm{CO}$ minus the IR spectra of the clean samples. CO coverage $\theta$ is considered to be equal to 1 after the $\mathrm{CO}$ pulse (saturated sample). The linear to bridge ratio $(\mathrm{L} / \mathrm{B})$ is measured at $\theta=1$ considering that the molar extinction coefficients do not depend on the adsorption mode.

$\delta$-Alumina surface sites were characterized by $\mathrm{CO}$ adsorption at low temperature $(77 \mathrm{~K})$ with FTIR recording of spectra on the Nicolet Nexus instrument. Pressed disks of pure catalysts samples were previously activated by outgassing under Ar flow $(50 \mathrm{ml} / \mathrm{min}, 10 \mathrm{~h})$ at $723 \mathrm{~K}$ in the IR cell. After cooling to the nitrogen liquid temperature, pulses of $\mathrm{CO}(1 \%$ in $\mathrm{Ar})$ are introduced until saturation. FTIR spectra are collected after every pulse.

\section{Results}

In the impregnation solutions, different molecular species were identified by UV-vis spectroscopy (Fig. 1). For nitrate solution, two absorption peaks are observed at $\lambda=285$ and $378 \mathrm{~nm}$. Because addition of $\mathrm{NaNO}_{3}$ enhanced the first peak, it was attributed to the electronic transition from the $n$ to the $\pi^{*}$ state in the free nitrate ions in agreement with literature data. The other absorption band at $\lambda=378 \mathrm{~nm}$ is assigned to a $\mathrm{d}-\mathrm{d}$ transition in the aquo complex $\mathrm{Pd}\left(\mathrm{H}_{2} \mathrm{O}\right)_{4}{ }^{2+}[41,42]$. UV-vis results show the non-complexant behavior of nitrate ions towards palladium metallic centers, nitrate ions remaining free in the solution. The palladium species in the starting acidic $(\mathrm{pH}$ $<1)$ solution is the tetra-aquo complex $\mathrm{Pd}\left(\mathrm{H}_{2} \mathrm{O}\right)_{4}{ }^{2+}$.

After sodium nitrite addition, modifications of the absorption spectrum are observed (Fig. 2). The two peaks at $\lambda=210$ and $280 \mathrm{~nm}$ are attributed to the square planar Pd complex $\mathrm{Pd}\left(\mathrm{NO}_{2}\right)_{4}{ }^{2-}$ in agreement with literature data [43-45] and the spectrum obtained from a $\mathrm{K}_{2} \mathrm{Pd}\left(\mathrm{NO}_{2}\right)_{4}$ solution.

The starting solution contains well-identified molecular species. In particular, the nitrate ion is not present in the

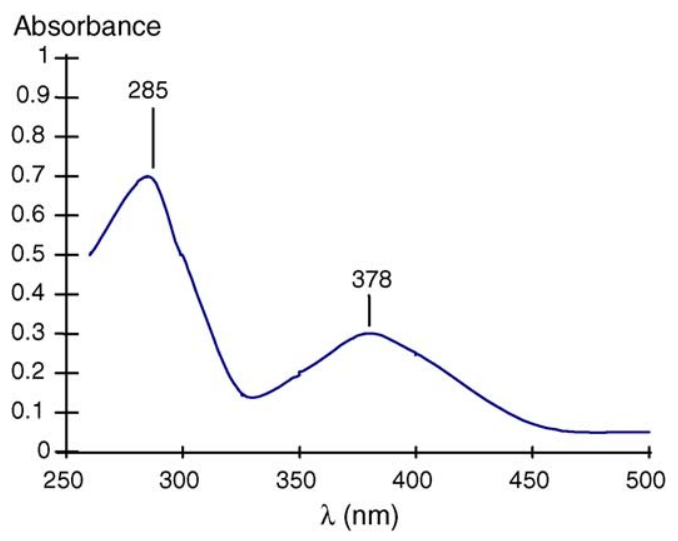

Fig. 1. UV-vis spectrum of a palladium nitrate solution $[\mathrm{Pd}]=0.2 \mathrm{~g} / 1$. 


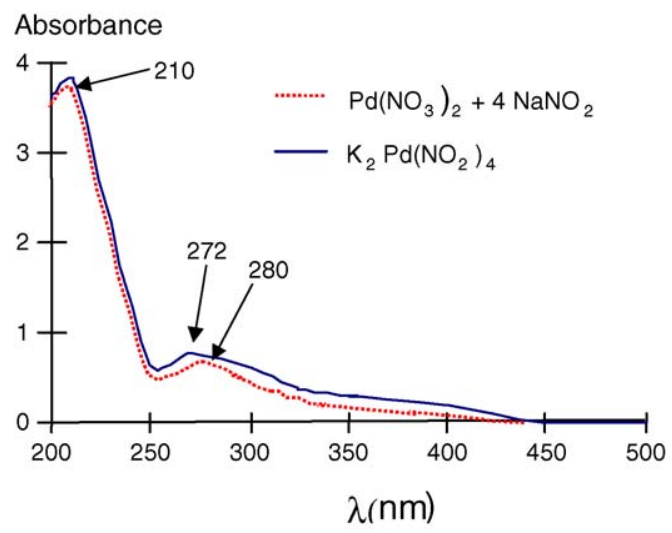

Fig. 2. UV-vis spectra of a palladium nitrate and sodium nitrite solution $[\mathrm{Pd}]=0.2 \mathrm{~g} / 1, \mathrm{NO}_{2} / \mathrm{Pd}=4 \mathrm{~mol} / \mathrm{mol}$ (dashed line) and a solution prepared from $\mathrm{K}_{2} \mathrm{Pd}\left(\mathrm{NO}_{2}\right)_{4},[\mathrm{Pd}]=0.2 \mathrm{~g} / 1$ (full line). co-ordination sphere of the palladium, whereas the nitrite ion, which is much more complexant, is observed. and the $\pi$ acceptor character of the $\mathrm{NO}_{2}{ }^{-}$ligand strongly stabilizes the complex by an-I inductive effect.

The two $\mathrm{Pd}\left[\mathrm{NO}_{2}\right]_{\mathrm{nw}}$ catalysts were analyzed by ThermoGravimetric Analysis in order to characterize the species present on the alumina surface after impregnation and drying steps. TGA analysis performed on $130 \mathrm{Pd} 1_{\mathrm{nw}}$ and $130 \mathrm{Pd} 2_{\mathrm{nw}}$ shows desorption of fragments characteristic of $\mathrm{H}_{2} \mathrm{O}(M=18 \mathrm{~g} /$ mol) for both samples at $373 \mathrm{~K}$. A second important loss of weight was also observed for the two samples from $673 \mathrm{~K}$ with desorbed $\mathrm{NO}_{x}$ fragments.

These results suggest that decomposition of the $\mathrm{Pd}\left(\mathrm{NO}_{2}\right)_{4}{ }^{2-}$ complex starts at temperatures above $673 \mathrm{~K}$. Thus, thermal treatments applied during catalysts preparation (drying at $393 \mathrm{~K}$, calcination at $473 \mathrm{~K}$ ) do not decompose the initial $\mathrm{Pd}\left(\mathrm{NO}_{2}\right)_{4}{ }^{2-}$ complex which is expected to be still present on the $\mathrm{Al}_{2} \mathrm{O}_{3}$ surface even after calcination at $473 \mathrm{~K}$.

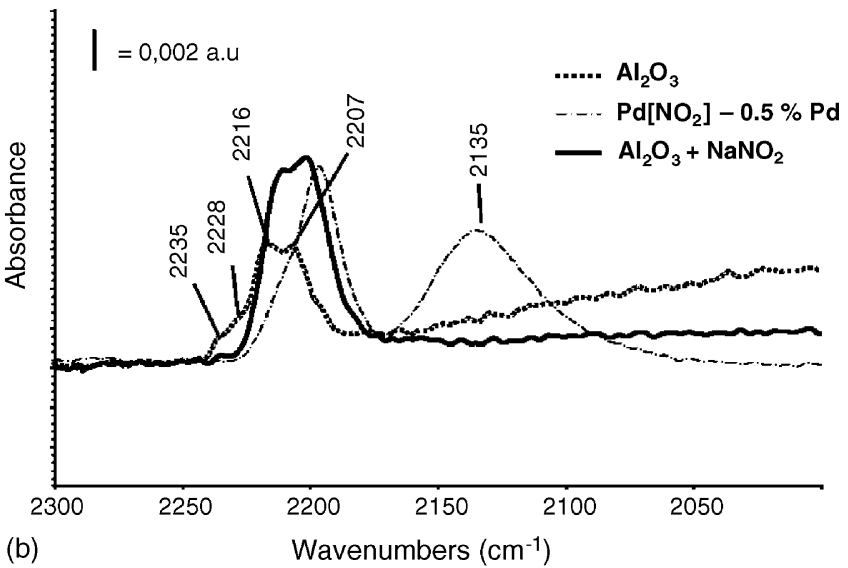

(b)
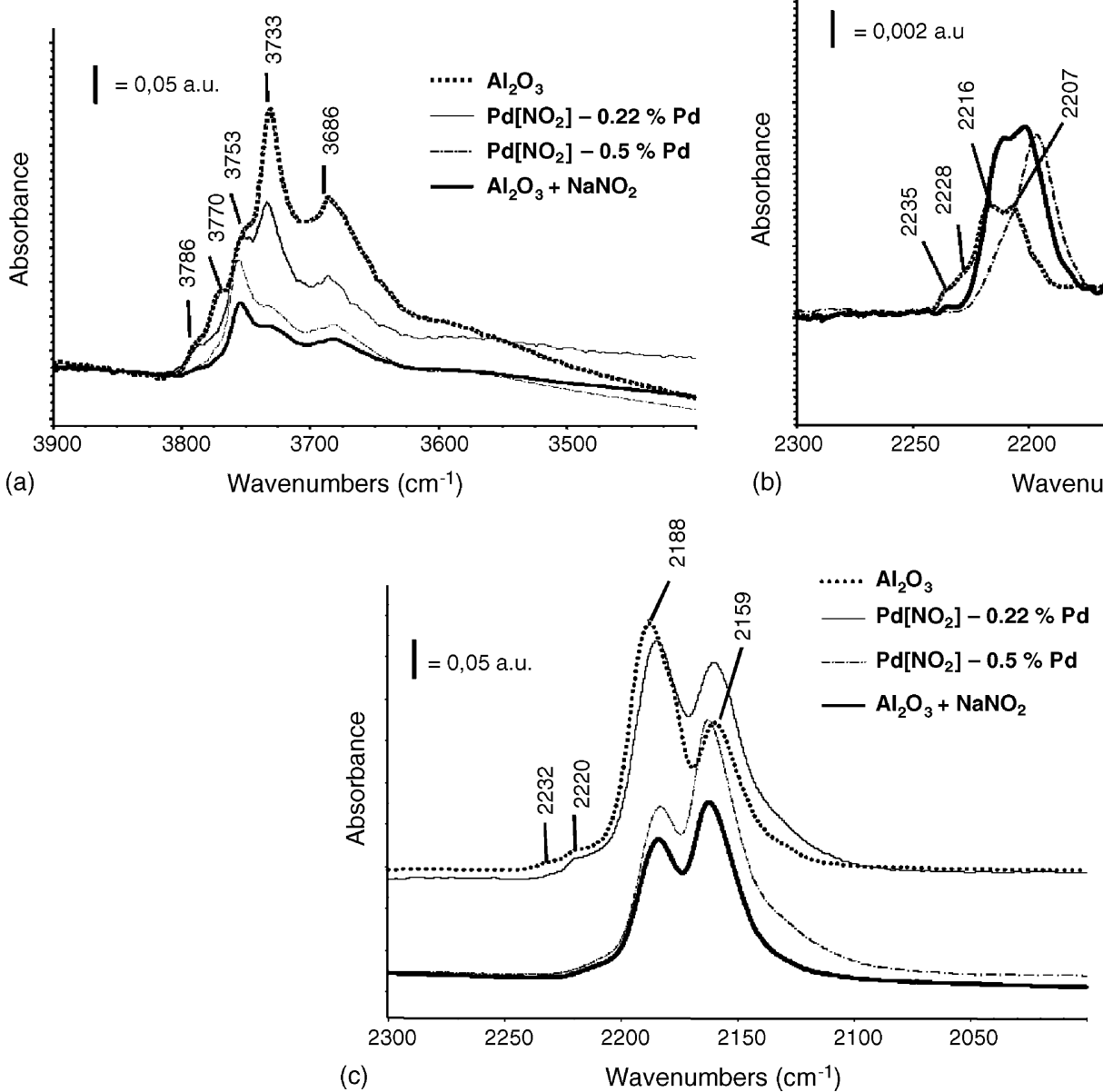

(c)

Wavenumbers $\left(\mathrm{cm}^{-1}\right)$

Fig. 3. (a) FTIR spectra of the $\delta$-alumina surface hydroxyl groups (3900-3400 $\mathrm{cm}^{-1}$ range): alumina support (bold dotted line), $130 \mathrm{Pd} 1_{\text {nw }}$ catalyst $(0.22 \%$ Pd) (fine line), $130 \mathrm{Pd} 2_{\mathrm{nw}}$ catalyst $(0.5 \% \mathrm{Pd})$ (fine dotted line), $\delta$-alumina impregnated with $\mathrm{NaNO}_{2}$ reagent (amount equivalent to the amount employed for the $130 \mathrm{Pd} 2_{\mathrm{nw}}$ $(0.5 \% \mathrm{Pd})$ catalyst preparation) (bold line); (b) FTIR spectra of adsorbed CO at low coverage $\left(P_{\mathrm{CO}}=2 \mathrm{mbar}\right)\left(2300-2050 \mathrm{~cm}^{-1}\right.$ range): CO adsorbed on $\delta$-alumina surface (bold dotted line), $\mathrm{CO}$ adsorbed on $130 \mathrm{Pd} 2_{\mathrm{nw}}$ catalyst $(0.5 \% \mathrm{Pd})$ (fine dotted line), $\mathrm{CO}$ adsorbed on $\delta$-alumina impregnated with $\mathrm{NaNO}_{2}$ reagent $($ amount equivalent to the amount employed for the $130 \mathrm{Pd} 2_{\mathrm{nw}}(0.5 \% \mathrm{Pd})$ catalyst preparation) (bold line); (c) FTIR spectra of adsorbed CO at high coverage $\left(P_{\mathrm{CO}}=100 \mathrm{mbar}\right)$ (2300-2050 $\mathrm{cm}^{-1}$ range): CO adsorbed on $\delta$-alumina surface (bold dotted line), CO adsorbed on $130 \mathrm{Pd} 1_{\text {nw }}$ catalyst $\left(0.22 \% \mathrm{Pd}\right.$ ) (fine line), CO adsorbed on $130 \mathrm{Pd} 2_{\mathrm{nw}}$ catalyst $(0.5 \% \mathrm{Pd})$ (fine dotted line), $\mathrm{CO}$ adsorbed on $\delta$-alumina impregnated with $\mathrm{NaNO}_{2}$ reagent (amount equivalent to the amount employed for the $130 \mathrm{Pd} 2_{\mathrm{nw}}$ $(0.5 \% \mathrm{Pd})$ catalyst preparation) (bold line). 
These two $\mathrm{Pd}\left[\mathrm{NO}_{2}\right]_{\mathrm{nw}}$ catalysts were also characterized by the Infrared Study of $\mathrm{CO}$ adsorption at low temperature. FTIR spectra of two references were recorded, the $\mathrm{Al}_{2} \mathrm{O}_{3}$ support alone and the $\mathrm{Al}_{2} \mathrm{O}_{3}$ support impregnated only with the $\mathrm{NaNO}_{2}$ salt (in the same amount as for the $130 \mathrm{Pd} 2_{\mathrm{nw}}$ catalyst). IR study of adsorption of $\mathrm{CO}$ at low temperature allows us to characterize the Lewis acid sites of the support in terms of strength (position of the $\mathrm{CO}$ stretching band) and amount (type of occupied Lewis sites by adsorbed $\mathrm{CO}$ in function of $\mathrm{CO}$ coverage).

FTIR spectra of the $3900-3400 \mathrm{~cm}^{-1}$ range (hydroxyl species region) are given on Fig. 3a. Different bands, characteristic of acid, neutral or basic hydroxyl groups are observed. The shouldering near $3786 \mathrm{~cm}^{-1}$ and the band at $3770 \mathrm{~cm}^{-1}$ are assigned to type I Al-OH basic hydroxyl groups (band at $3770 \mathrm{~cm}^{-1}$ : type Ia basic $\mathrm{Al}^{\mathrm{IV}}-\mathrm{OH}$ hydroxyl group, band at $3786 \mathrm{~cm}^{-1}$ : type $\mathrm{Ib} \mathrm{Al}{ }^{\mathrm{VI}}-\mathrm{OH}$ basic hydroxyl group). The two bands at 3733 and $3753 \mathrm{~cm}^{-1}$ correspond to type II neutral hydroxyl groups (band at $3733 \mathrm{~cm}^{-1}$ : type IIa neutral hydroxyl groups, band at $3753 \mathrm{~cm}^{-1}$ : type IIb neutral hydroxyl group). The band at $3686 \mathrm{~cm}^{-1}$ is ascribed to type III Al ${ }^{\mathrm{VI}}-\mathrm{OH}$ acid hydroxyl groups [46]. The broad and weakly intense band at $3600 \mathrm{~cm}^{-1}$ is due to hydrogen bond between hydroxyl groups.

Values of the ratio between the neutral type IIb hydroxyl group $\left(3753 \mathrm{~cm}^{-1}\right)$ to the neutral type IIa $\left(3733 \mathrm{~cm}^{-1}\right)$ or type III hydroxyl group $\left(3686 \mathrm{~cm}^{-1}\right)$ are reported on Table 1 for the $130 \mathrm{Pd} 1_{\mathrm{nw}}$ sample $(0.22 \% \mathrm{Pd}), 130 \mathrm{Pd} 2_{\mathrm{nw}}$ catalyst $(0.5 \% \mathrm{Pd})$ and alumina support impregnated with only the $\mathrm{NaNO}_{2}$ reagent in the same amount than in the case of $130 \mathrm{Pd} 2_{\mathrm{nw}}$ catalyst. When alumina is impregnated with solutions containing either $\mathrm{Pd}\left(\mathrm{NO}_{2}\right)_{4}{ }^{2-}$ precursor or only $\mathrm{NaNO}_{2}$, the intensity of all the different hydroxyl bands is reduced. Bands at 3733 and $3686 \mathrm{~cm}^{-1}$, assigned respectively to neutral IIa hydroxyl groups and $\mathrm{Al}^{\mathrm{VI}}-\mathrm{OH}$ type $\mathrm{III}$ acid hydroxyl groups are particularly affected. For the $130 \mathrm{Pd} 1_{\mathrm{nw}}$ sample, the IIb/IIa ratio increases up to 0.8 ( 1.3 for the IIb/III). For the more Pd loaded $130 \mathrm{Pd} 2_{\mathrm{nw}}$ catalyst $(0.5 \% \mathrm{Pd})$, these ratios are also modified in favor of the type IIb hydroxyl group (1.6 and 1.8). The same modification of the IIb/IIa and IIb/III ratio in favor of the type IIb hydroxyl groups is observed for the alumina impregnated with only the $\mathrm{NaNO}_{2}$ reagent for the same amount than in the case of $130 \mathrm{Pd} 2_{\mathrm{nw}}$ catalyst.

Thus, the $\mathrm{Pd}\left(\mathrm{NO}_{2}\right)_{4}{ }^{2-}$ complex or the free anions $\mathrm{NO}_{2}{ }^{-}$ (brought by $\mathrm{NaNO}_{2}$ ) interact selectively with the neutral type $\mathrm{IIa}$ and type $\mathrm{III}$ acid $\mathrm{Al}^{\mathrm{VI}}-\mathrm{OH}$ hydroxyl groups. Moreover, since the two FTIR spectra for the $130 \mathrm{Pd} 2_{\mathrm{nw}}(0.5 \% \mathrm{Pd})$ catalyst and

Table 1

Ratio of the FTIR peak of the surface hydroxyl groups for the starting alumina, $\mathrm{NaNO}_{2}$ impregnated alumina, and two catalysts with different Pd loading

\begin{tabular}{lll}
\hline Reference & $\begin{array}{l}\mathrm{IIb}\left(3753 \mathrm{~cm}^{-1}\right) / \mathrm{IIa} \\
\left(3733 \mathrm{~cm}^{-1}\right)\end{array}$ & $\begin{array}{l}\mathrm{IIb}\left(3753 \mathrm{~cm}^{-1}\right) / \mathrm{III} \\
\left(3686 \mathrm{~cm}^{-1}\right)\end{array}$ \\
\hline$\delta-\mathrm{Al}_{2} \mathrm{O}_{3}$ & 0.6 & 0.8 \\
$\mathrm{NaNO}_{2} / \delta-\mathrm{Al}_{2} \mathrm{O}_{3}$ & 1.6 & 1.8 \\
$130 \mathrm{Pd} 1_{\text {nw }}(0.22 \% \mathrm{Pd})$ & 0.8 & 1.3 \\
$130 \mathrm{Pd} 2_{\text {nw }}(0.5 \% \mathrm{Pd})$ & 1.6 & 1.8 \\
\hline
\end{tabular}

for the $\mathrm{NaNO}_{2}$ impregnated $\delta$-alumina are quite similar, it is difficult to establish whether the $\mathrm{Pd}\left(\mathrm{NO}_{2}\right)_{4}{ }^{2-}$ complex interacts with the alumina surface hydroxyl groups through an adsorption with ligand exchange or if hydroxyl groups peaks consumption are only representative of the cationic exchange of the counter ion $\mathrm{Na}^{+}$with to form $\mathrm{Al}-\mathrm{O}-\mathrm{Na}$ surface groups.

In order to have a better understanding of the interaction of the precursor with the surface, $\mathrm{CO}$ adsorption at $77 \mathrm{~K}$ followed by FTIR analysis was performed. FTIR spectra in the 2300 $2050 \mathrm{~cm}^{-1}$ range (CO stretching region) are given Fig. $3 \mathrm{~b}$ for a low CO coverage and Fig. $3 \mathrm{c}$ for a high CO coverage. Different bands characteristic of $\mathrm{CO}$ adsorbed on Lewis acid sites of different strength are observed. The $\mathrm{CO}$ stretching bands at 2235 and $2228 \mathrm{~cm}^{-1}$ are assigned to $\mathrm{CO}$ adsorbed on strong Lewis acid sites. The CO stretching band at $2200-2180 \mathrm{~cm}^{-1}$ corresponds to $\mathrm{CO}$ adsorbed on medium and weak Lewis acid sites. The band at $2159 \mathrm{~cm}^{-1}$ (Fig. 3c) is ascribed to hydrogen bonds between $\mathrm{CO}$ and neutral hydroxyl groups of the alumina surface $[47,48]$.

Another band at $2135 \mathrm{~cm}^{-1}$ is also visible on the FTIR spectrum of the $130 \mathrm{Pd} 2_{\mathrm{nw}}$ catalyst at low CO coverage (Fig. 3b). This band could be characteristic of $\mathrm{CO}$ adsorption on slightly oxidized $\mathrm{Pd}^{\delta+}$ species [49]. It is known that, bands characteristic of $\mathrm{CO}$ adsorption on $\mathrm{Pd}^{0}$ are located at lower frequencies (below $2100 \mathrm{~cm}^{-1}$ ), bands characteristic of $\mathrm{CO}$ adsorption on $\mathrm{Pd}^{2+}$ species are located at higher frequencies (2215-2145 $\mathrm{cm}^{-1}$ range). On the $\delta$-alumina support, for both $\mathrm{CO}$ coverages (Figs. $3 \mathrm{~b}$ and 5), the characteristic bands of $\mathrm{CO}$ adsorption on strong, medium and weak Lewis acid sites are clearly visible.

Extinction of bands characteristic of $\mathrm{CO}$ adsorption on strong acid Lewis sites $\left(2232-2220 \mathrm{~cm}^{-1}\right)$ as well as an important decrease of the band characteristic of $\mathrm{CO}$ adsorption on medium and weak Lewis acid sites $\left(2188 \mathrm{~cm}^{-1}\right)$ are observed for the $130 \mathrm{Pd} 2_{\mathrm{nw}}(0.5 \% \mathrm{Pd})$ catalyst and for impregnated alumina with a $\mathrm{NaNO}_{2}$ solution at high $\mathrm{CO}$ coverages. Bands characteristic of $\mathrm{CO}$ adsorption on strong Lewis acid sites are still present and bands of $\mathrm{CO}$ adsorbed on medium and weak Lewis acid sites are not yet affected (Fig. 3c) for the $130 \mathrm{Pd} 1_{\mathrm{nw}}(0.22 \% \mathrm{Pd})$ catalyst. At low Pd loading, a significant part of the strong Lewis acid sites is still accessible to $\mathrm{CO}$ adsorption. In conclusion, interaction between $\mathrm{Pd}\left(\mathrm{NO}_{2}\right)_{4}{ }^{2-}$ complex salt occurs firstly with strong Lewis acid sites and afterwards with medium and weak Lewis acid sites when increasing metal loading. These have already been observed for other precursors in different studies [50,51]. Comparison with adsorption of free $\mathrm{NO}_{2}{ }^{-}$anions (in the case of impregnation of $\mathrm{NaNO}_{2}$ ), allows to suppose that this interaction proceeds mainly through nucleophilic ligands with surface Lewis sites instead of electrophilic centers (Pd) on surface hydroxyl groups.

Compositions and particle sizes obtained from $\mathrm{CO}$ chemisorption measurements are presented in Table 2. For all the catalysts, particles sizes are very similar, and below $1 \mathrm{~nm}$. No artifact due to the presence of sodium is expected for the nitrite precursor because concentrations are very close to each other and very low, corresponding to the residual amount 
Table 2

Main characteristics of the catalysts

\begin{tabular}{lllr}
\hline Reference & wt.\% Pd & $\begin{array}{l}\text { Particle size from CO } \\
\text { chemisorption }(\mathrm{nm})\end{array}$ & Na (ppm) \\
\hline $130 \mathrm{Pd}[\mathrm{acac}]$ & 0.30 & 1.00 & - \\
$200 \mathrm{Pd}[\mathrm{acac}]$ & 0.48 & 1.00 & - \\
$\mathrm{Pd}\left[\mathrm{NO}_{2}\right]$ & & & \\
$130 \mathrm{Pd} 1_{\mathrm{nw}}$ & 0.22 & 0.82 & 2455 \\
$130 \mathrm{Pd} 2_{\mathrm{nw}}$ & 0.50 & 0.92 & 4730 \\
$130 \mathrm{Pd} 2$ & 0.09 & 0.79 & 102 \\
$130 \mathrm{Pd} 3$ & 0.17 & 0.93 & 308 \\
$130 \mathrm{Pd} 4$ & 0.30 & 0.86 & 211 \\
$130 \mathrm{Pd} 5$ & 0.56 & 0.89 & $<100$ \\
$200 \mathrm{Pd} 1$ & 0.08 & 0.73 & $<100$ \\
$200 \mathrm{Pd} 2$ & 0.15 & 0.84 & $<100$ \\
$200 \mathrm{Pd} 3$ & 0.23 & 0.89 & 230 \\
$200 \mathrm{Pd} 4$ & 0.42 & 0.86 & \\
\hline
\end{tabular}

initially present on the alumina carrier. Most of the sodium resulting from the preparation itself has been removed by washing procedure.

For all the catalysts $\left(\left[\mathrm{NO}_{2}\right]\right.$ and [acac] precursors), the distribution of the $\mathrm{Pd}$ in the alumina beads is very homogeneous as shown by Castaing $\mu$ probe analysis (Fig. 4) at least at the resolution limit of the method which is around $1 \mu \mathrm{m}$. Except for the 130Pd5 catalyst, electron microscopy observations, even performed in the dark field mode in order to increase the contrast between metallic particle and the support, did not allow visualization of the Pd particles. One can admit that the upper limit of the particles size corresponds to the detection limit of the microscope, circa $0.7 \mathrm{~nm}$ in good agreement with the $\mathrm{CO}$ chemisorption results previously presented. As an example, the micrographs obtained for one catalyst (200Pd4) and presented in Fig. 5 illustrates the absence of visible Pd particles. Concerning the catalyst $130 \mathrm{Pd} 5$, particles of $0.8 \mathrm{~nm}$ in mean diameter were observed, just above the detection limit. A highly homogeneous distribution on the alumina plates is also observed and in conclusion the homogeneity of the deposit can be considered uniform at a nanometric scale (Fig. 6).

Fig. 7 shows the quality of agreement obtained in $k$-space between filtered experimental data and numerical simulation for the Pd K-edge EXAFS spectrum of the 200Pd4 catalyst. Note that the numerical simulation corresponds to a typical residual in the order of $10^{-2}$. A two-shell ( $\mathrm{Pd}-\mathrm{Pd}$ and $\left.\mathrm{Pd}-\mathrm{O}\right)$ least-squares fitting procedure (in $k$-space) using a single scattering EXAFS formulation was used to extract the co-ordination number $(N)$, distance $(R)$ and Debye-Waller factor $(\Delta \sigma)$. Structural parameters (nature of the neighbors,
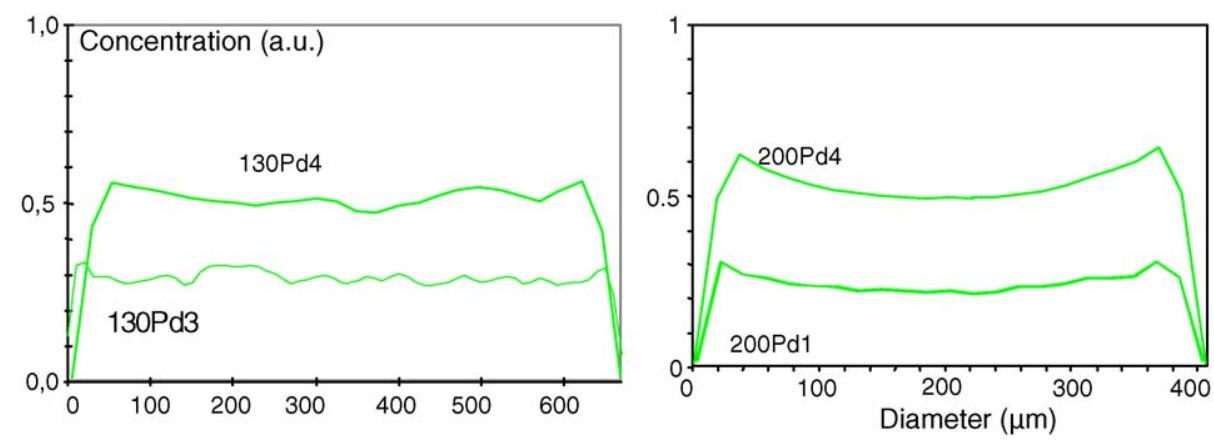

Fig. 4. Pd repartition across the alumina beads by Castaing $\mu$ probe analysis for different catalysts.
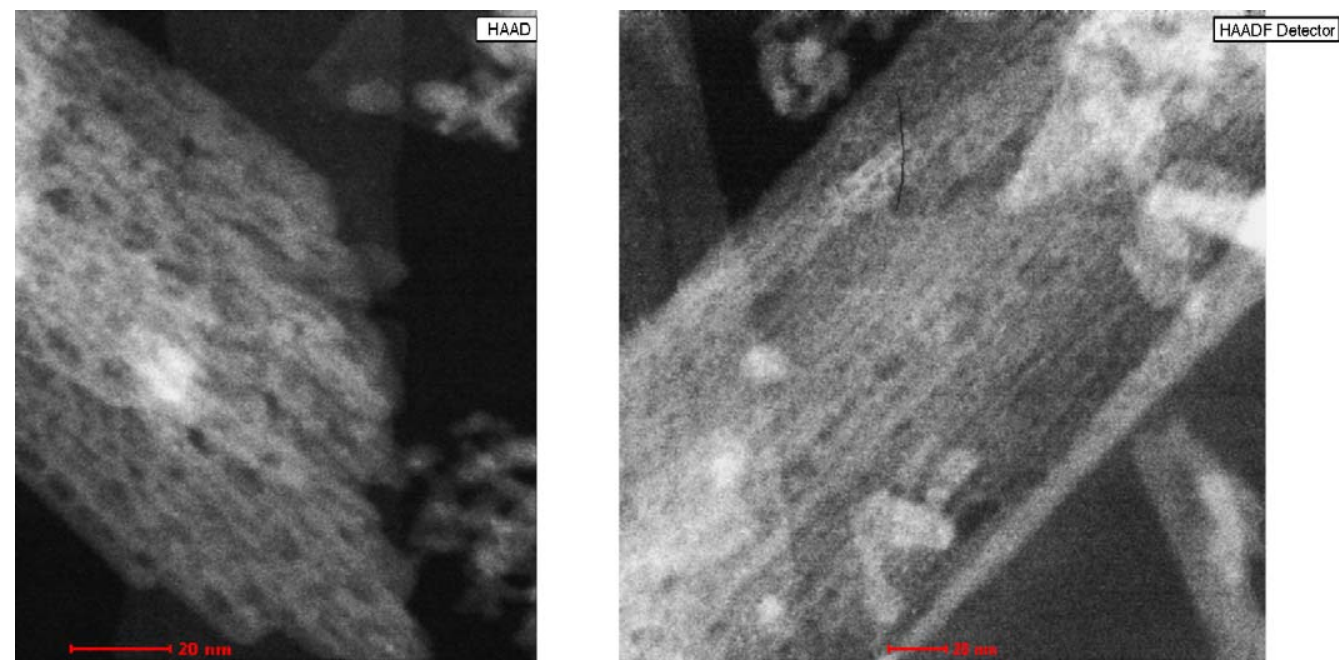

Fig. 5. HAADF microscopy observations for the 200Pd4 catalyst. 


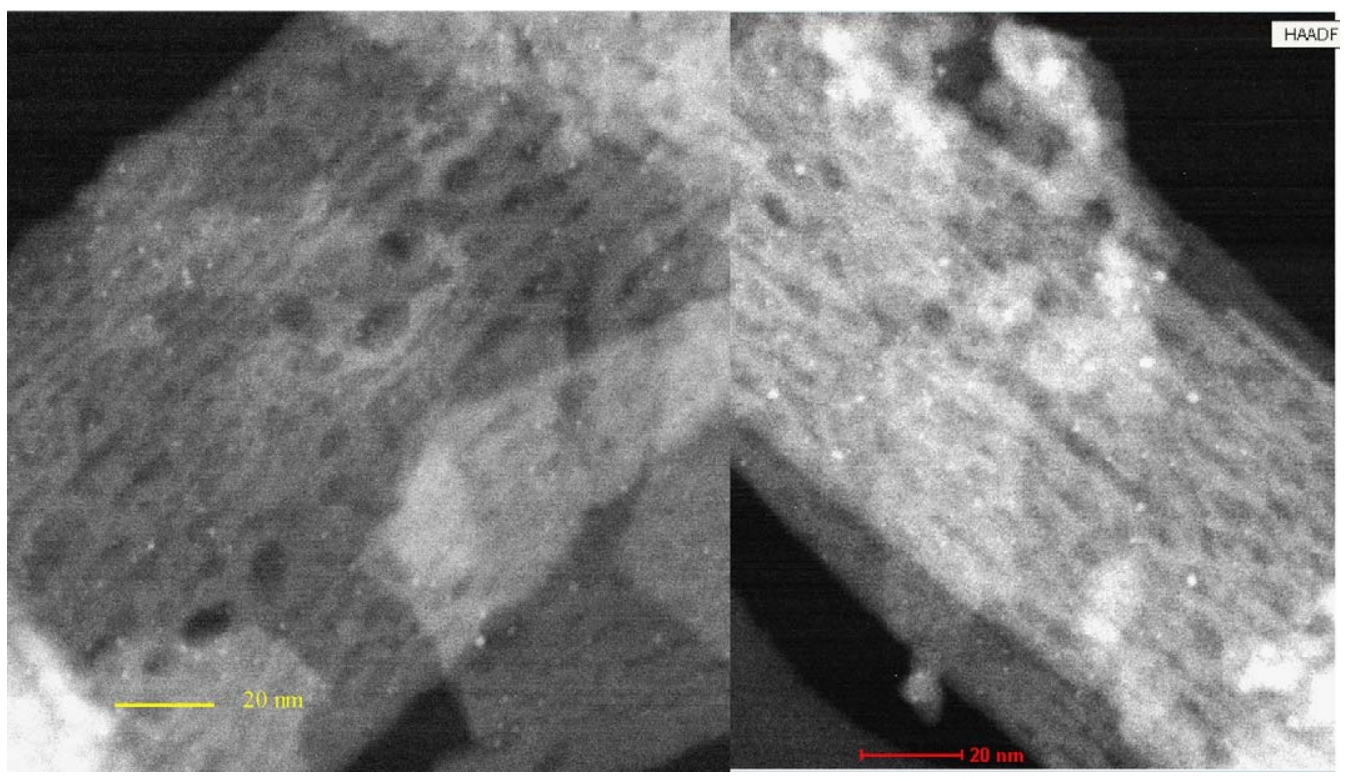

Fig. 6. HAADF microscopy observations for the 130Pd5 catalyst.

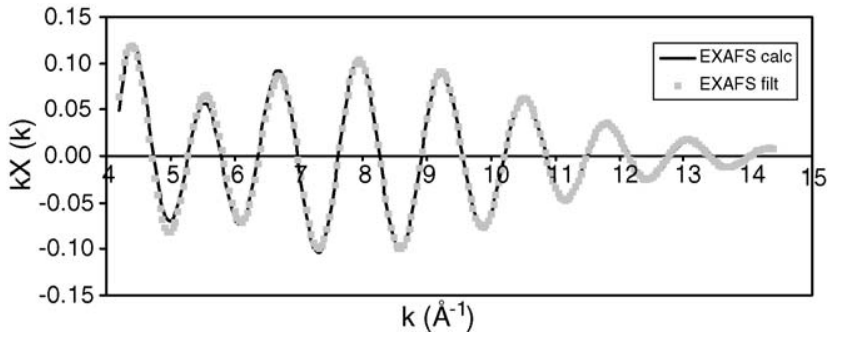

Fig. 7. Experimental and theoretical curves of the FT modulus and EXAFS oscillations for the $200 \mathrm{Pd} 4$ reduced catalyst.

co-ordination numbers, inter-atomic distance and DebyeWaller factor) of the reference compounds used in this study and for different catalysts are summarized in Table 3. One can notice that only $\mathrm{Pd}$ neighbors are found to be present at the $\mathrm{Pd}$ edge at a distance close to the bulk Pd-Pd value $(2.75 \AA$ ) which shows that $\mathrm{Pd}$ is fully reduced and no strong interaction exist with atoms of the support $(\mathrm{Al}, \mathrm{O})$. Analysis of the white line intensity by XANES also confirms the reduced nature of the Pd after reduction treatment at $473 \mathrm{~K}$.

Assuming a spherical shape of the particles, an estimation of the mean diameter can be obtained from the EXAFS results using the Borowski relation between the mean diameter of a spherical particle and the number of neighbors in the first shell [52,53] (Table 3). The values are in agreement with the TEM and $\mathrm{CO}$ chemisorption measurements.
All these characterization results suggest that the catalysts have no significant differences in terms of size and morphology of the supported particles. The number of particles per surface area unit is the main parameter which changes from one catalyst to another. Indeed, if one assumes that the surface density is kept constant, then the range of particle size should vary by a factor 1.7 considering the different metal loadings. However, this factor is only 1.2 if we consider the different sizes obtained from EXAFS results. Thus, the increase of the Pd loading necessarily induces an increase of particle surface density in a quasi proportional dependence.

In order to estimate the particle surface density of the different catalysts, we consider that all the particles contain 10 atoms with a three-dimensional semi cubo-octahedral structure as presented (Fig. 8) and proposed by Frenkel [54]. The mean co-ordination number of $\mathrm{Pd}$ atoms for this particle shape is 4.8 close to EXAFS results (Table 3). From this hypothesis, it is then possible to evaluate for each catalyst the mean particle surface density. Table 4 summarizes these values for the two set of catalysts.

XPS results are presented in Table 5 and Fig. 9. For the oxidized $\mathrm{Pd}\left[\mathrm{NO}_{2}\right]$ catalysts, the binding energy (BE) $\mathrm{Pd}$ 3d5/2 value is very high $(337 \mathrm{eV})$, being between the $\mathrm{PdO}(336.6 \mathrm{eV})$ and the $\mathrm{PdO}_{2}(338 \mathrm{eV})$ [55] binding energies. This result is consistent with the fact that low calcination temperature treatment does not decomposes the $\mathrm{Pd}\left(\mathrm{NO}_{2}\right)_{4}{ }^{2-}$ complex.

Table 3

Nature and number of neighbors at the K-edge of Pd for samples 130Pd3-4 and 200Pd3-4 after an in situ reduction $2 \mathrm{~h}$ at $473 \mathrm{~K}$

\begin{tabular}{|c|c|c|c|c|c|}
\hline Reference & $\begin{array}{l}\text { Nature of } \\
\text { neighbors }\end{array}$ & $\begin{array}{l}\text { Number of } \\
\text { neighbors } N\end{array}$ & $\begin{array}{l}\text { Distances } d \\
(\AA)( \pm 0.05)\end{array}$ & $\begin{array}{l}\text { Debye-Waller } \\
\text { factor } \Delta \sigma(\AA)\end{array}$ & $\begin{array}{l}\text { Mean diameter } \\
\text { of } \mathrm{Pd} \text { particles }(\mathrm{nm})\end{array}$ \\
\hline $130 \mathrm{Pd} 3$ & $\mathrm{Pd}$ & $4.9 \pm 1.0$ & 2.75 & 0.07 & $0.68 \pm 0.12$ \\
\hline $130 \mathrm{Pd} 4$ & $\mathrm{Pd}$ & $5.3 \pm 0.5$ & 2.72 & 0.06 & $0.71 \pm 0.06$ \\
\hline $200 \mathrm{Pd} 3$ & $\mathrm{Pd}$ & $5.9 \pm 0.5$ & 2.74 & 0.07 & $0.75 \pm 0.25$ \\
\hline $200 \mathrm{Pd} 4$ & $\mathrm{Pd}$ & $5.6 \pm 0.5$ & 2.76 & 0.05 & $0.79 \pm 0.07$ \\
\hline
\end{tabular}




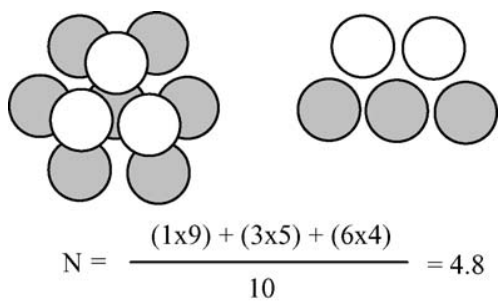

Fig. 8. Structure of the particles (up and side view) containing 10 atoms with a mean co-ordination of 4.8 .

This high binding energy value can be explained by the strong -I inductive effect of the nitrite ligands. After reduction, binding energy decreases when surface particle density increases, for the two supports the drop is similar and about $0.4 \mathrm{eV}$. Moreover, for a same value of particle surface density, there is no significant variation of the binding energy with the nature of the alumina support. Keeping in mind that all the catalysts have the same particle size, we can exclude a size effect or a final state effect to interpret this result as it is widely reported in the literature [5660]. A relative variation of the intrinsic electronic properties of the particles is thus proposed leading to a negative shift (decreasing BE) when particle surface density increases. Concerning Pd[acac] catalysts, binding energy seems to fit also with the curve, with the same low values than for the corresponding high values of particle density.

Table 4

Mean surface density of particles for the two sets of catalysts

\begin{tabular}{llll}
\hline Reference & wt.\% Pd & $\begin{array}{l}\text { Particle size } \\
\text { from CO } \\
\text { chemisorption }(\mathrm{nm})\end{array}$ & $\begin{array}{l}\text { Mean surface } \\
\text { density of particles } \\
\left.\text { (nb of particles } / \mathrm{nm}^{2}\right)\end{array}$ \\
\hline 130Pd[acac] & 0.30 & 1.00 & 13000 \\
200Pd[acac] & 0.48 & 1.00 & 13500 \\
Pd[NO $\left.{ }_{2}\right]$ & & & \\
130Pd2 & 0.09 & 0.79 & 4050 \\
$130 \mathrm{Pd} 3$ & 0.17 & 0.93 & 7220 \\
$130 \mathrm{Pd} 4$ & 0.30 & 0.86 & 12880 \\
$130 \mathrm{Pd} 5$ & 0.56 & 0.89 & 24200 \\
$200 \mathrm{Pd} 1$ & 0.08 & 0.73 & 2240 \\
$200 \mathrm{Pd} 2$ & 0.15 & 0.84 & 4700 \\
$200 \mathrm{Pd} 3$ & 0.23 & 0.89 & 6500 \\
$200 \mathrm{Pd} 4$ & 0.42 & 0.86 & 11880 \\
\hline
\end{tabular}

Table 5

Binding energies of the $\mathrm{Pd}_{3 \mathrm{~d} 5 / 2}$ photopic (eV) for the 130Pd and 200Pd catalysts dried $2 \mathrm{~h}$ at $473 \mathrm{~K}$ under air flow and reduced $2 \mathrm{~h}$ at $473 \mathrm{~K}$ under hydrogen

\begin{tabular}{lcl}
\hline Reference & $\mathrm{BE} \mathrm{Pd}_{\text {dried } 3 \mathrm{~d} 5 / 2}(\mathrm{eV}) \pm 0.1$ & $\mathrm{BE} \mathrm{Pd}_{\text {reduced } 3 \mathrm{~d} 5 / 2}(\mathrm{eV}) \pm 0.1$ \\
\hline 130Pd[acac] & - & 335.5 \\
200Pd[acac] & - & 335.5 \\
130Pd2 & - & 336.1 \\
$130 \mathrm{Pd} 3$ & 337.0 & 335.9 \\
$130 \mathrm{Pd} 4$ & 337.3 & 335.7 \\
$200 \mathrm{Pd} 1$ & - & 335.6 \\
$200 \mathrm{Pd} 2$ & - & 336.1 \\
$200 \mathrm{Pd} 3$ & - & 336.0 \\
$200 \mathrm{Pd} 4$ & - & 335.8 \\
\hline
\end{tabular}

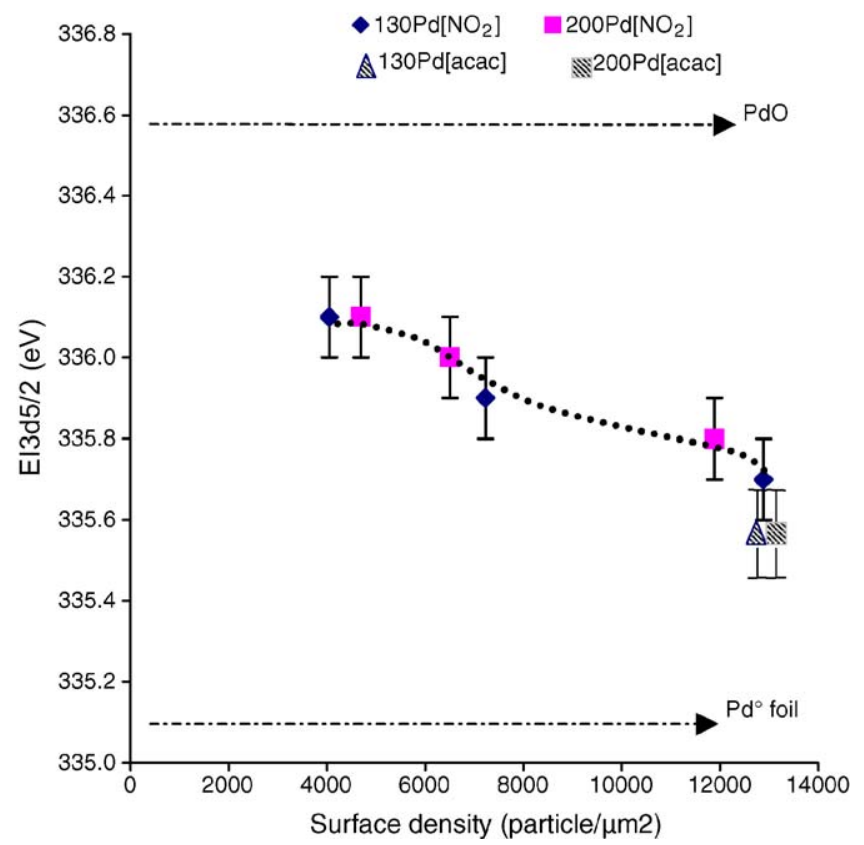

Fig. 9. Binding energy of the $\mathrm{Pd}_{3 \mathrm{~d} 5 / 2}$ for the two set of catalysts.

FTIR (CO) spectrum (Fig. 10) shows classical absorption band for $\mathrm{CO}$ on Pd with linear form between 2000 and $2100 \mathrm{~cm}^{-1}$ and bridged species comprised between 1800 and $2000 \mathrm{~cm}^{-1}$ [61]. For all the catalysts the absence of any detectable bands at $2100-2150 \mathrm{~cm}^{-1}$, typical of adsorption of $\mathrm{CO}$ on oxidized $\mathrm{Pd}^{\delta+}$ species, confirms that palladium is fully reduced which is consistent with the TPR and XANES Pd Kedge results.

Linear to bridged adsorbed $\mathrm{CO}$ ratios (L/B) determined at saturation are presented in Table 6 . No significant differences can be observed between the catalysts within the accuracy of the method. Surface density and the nature of the alumina does not affect this parameter. The value of these ratio are quite high showing that linear adsorbed $\mathrm{CO}$ is favored in agreement with very small three-dimensional particles picture previously proposed [61,62].

Variations of the position of the linearly adsorbed $\mathrm{CO}$ stretching band with surface coverage $(\theta)$ are presented in Fig. 11 and wavenumber taken for $\theta$ close to zero versus particle density in Fig. 12. One can observe that linear CO band decreases when the surface density increases for the two supports. Large differences, $25 \mathrm{~cm}^{-1}$ for Pd200 set and $30 \mathrm{~cm}^{-1}$ for the Pd130 set, between low and high surface density, are found. These variations are much larger than the precision of the technique.

The lowering of the wavenumber when particle density increases can be related to a stronger retrodonation phenomenon from surface metal atoms to $\mathrm{CO} 2 \pi^{*}$ antibonding orbitals, weakening the $\mathrm{CO}$ bond [63]. Moreover, for a given particle density, no significant difference is observed between the two alumina supports.

For the Pd[acac] catalysts, absorption bands are shifted towards higher values for the same particle surface density. 


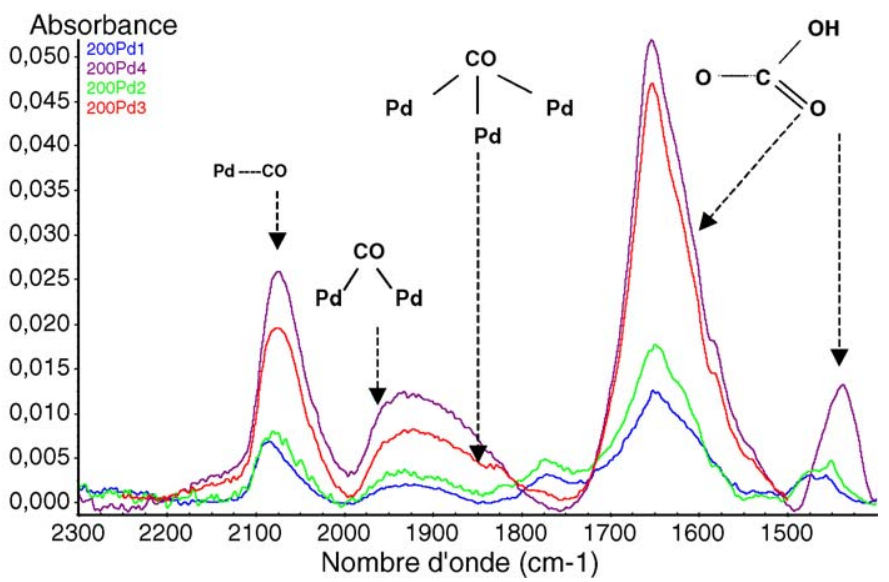

Fig. 10. IR(CO) spectra showing the different adsorbed $\mathrm{CO}$ species.

Table 6

Linear to bridged ratios measured at saturation

\begin{tabular}{ll}
\hline Reference & L/P \\
\hline $200 \mathrm{Pd} 1$ & $1.32 \pm 0.10$ \\
$200 \mathrm{Pd} 2$ & $1.12 \pm 0.14$ \\
$200 \mathrm{Pd} 3$ & $1.55 \pm 0.25$ \\
$200 \mathrm{Pd} 4$ & $1.27 \pm 0.40$ \\
$130 \mathrm{Pd} 2$ & $1.09 \pm 0.23$ \\
$130 \mathrm{Pd} 3$ & $1.55 \pm 0.38$ \\
$130 \mathrm{Pd} 4$ & $1.31 \pm 0.23$ \\
$130 \mathrm{Pd} 5$ & $0.94 \pm 0.11$ \\
\hline
\end{tabular}

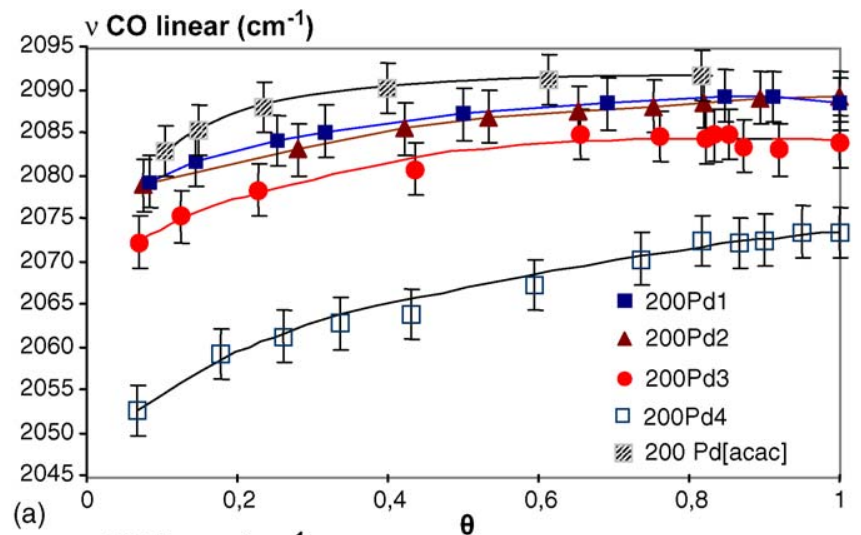

(a) $\checkmark$ CO linear $\left(\mathrm{cm}^{-1}\right)$

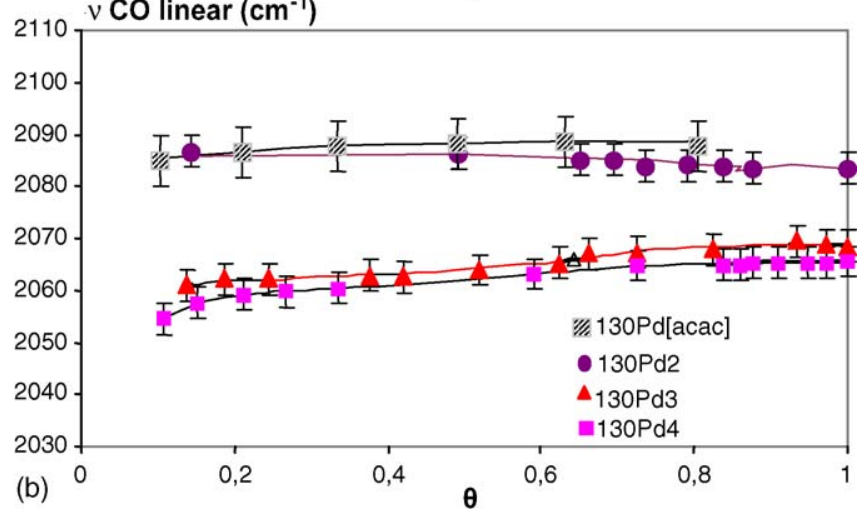

Fig. 11. Variation of the $\nu \mathrm{CO}$ linear for the Pd200 (a) and Pd130 (b) sets.

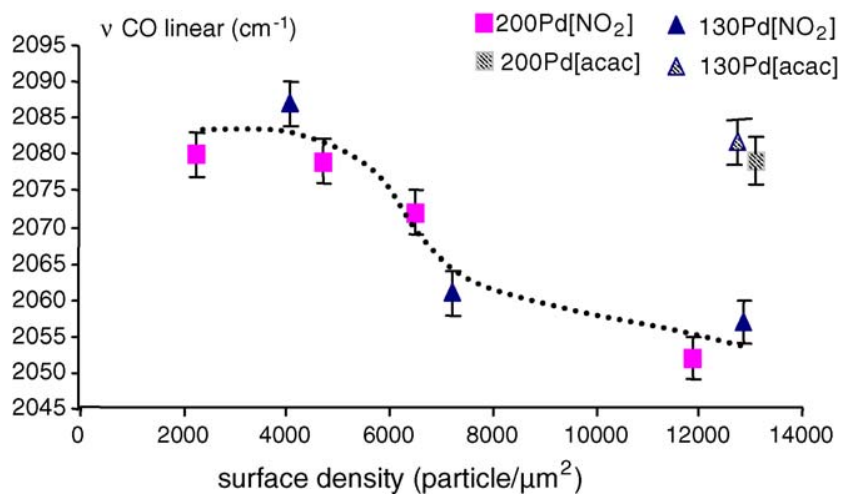

Fig. 12. Vibration frequency of the linear $\mathrm{CO}$ at the lowest surface coverage for the two sets of catalysts.

According to these results, for a same particle size and surface density, backdonation phenomenon is less intense with these particles due to higher metal-support interaction. Stronger metal-support interaction was proposed for this type of catalyst [64] pointed out for instance by EXAFS results [65] showing $\mathrm{Pd}-\mathrm{O}_{\text {support }}$ bonds, even after reduction under $\mathrm{H}_{2}$, generated by high temperature calcination needed to remove acetylacetone ligand. Finally, one can notice that in the case of these two catalysts, the values of $\nu \mathrm{CO}_{\text {linear }}$ (high) and binding energy $\mathrm{Pd}_{3 \mathrm{~d} 5 / 2}$ (low) does not follow the same tendency as for catalysts prepared from nitrite salt at the same particle density.

\section{Discussion}

Study of supported particles with a sub nanometric size is a rather difficult task mainly due to the fact that this range of size is near the detection limit of most of the analytical tools. For this purpose, we used in this work a multitechnique approach, combining local and global information, in order to have high confidence in the final description of the supported particles' characteristics. Comparison between average values given by global methods such as EXAFS, chemisorption and more local techniques (HAADF STEM) gave a rather good agreement and allows us to define the lower and upper limit of the particle size for each catalysts. The particle size of the $\left[\mathrm{PdNO}_{2}\right]$ catalysts range from 0.7 to circa $0.9 \mathrm{~nm}$ as shown by EXAFS or CO chemisorption measurements. Beyond the slight difference between results obtained from the different techniques, one can conclude that the particle size distributions of the different catalysts are very narrow, and no significant difference is shown in terms of size and shape of the palladium particles (IR and EXAFS results) for the different catalysts with different metal loadings. Moreover, palladium nanoparticles are uniformly dispersed on the alumina supports, with no Pd enriched or depleted zones as shown by Castaing Microprobe and TEM (HAADF mode).

From these particles size values and a hypothesis of cluster shape, a range of mean atom number per particles (surface density) was proposed so that the mean number of particle per surface area has been evaluated. Despite the large number of papers devoted on the study of supported nanoparticles, little 
attention has been paid to the role in catalysis of particle surface density or a related characteristic which is the inter-particle distance even if several authors underlined its importance in catalysis [66]. We observe in this work a large variation of the electronic properties as shown by FTIR(CO) and XPS results with the particle surface density, keeping constant the other characteristics, mainly the particle size. The increase of particle surface density decreases both the binding energy of core level of Pd atoms (3d5/2) and the position of the linearly adsorbed $\mathrm{CO}$ stretching band. The origin of these variations may be different metal-support interactions as a function of the metal loading as shown by FTIR characterization. The particular metal-support interactions shown in this work come from the $\mathrm{Pd}\left[\mathrm{NO}_{2}\right]$ catalyst preparation method. Indeed, catalysts are prepared by impregnation of a solution containing a molecular $\mathrm{Pd}\left(\mathrm{NO}_{2}\right)_{4}{ }^{2-}$ precursor. The square planar $\mathrm{Pd}\left(\mathrm{NO}_{2}\right)_{4}{ }^{2-}$ complex is very stable, as shown by the very high value of its formation constant $\left(10^{21}\right)$ [67] and protected against nucleophilic attack of basic hydroxyl surface groups of the support, so that no inorganic polymerization via olation processes can occur when contacting with alumina support [68]. This molecular complex is uniformly distributed on alumina surface (Castaing $\mu$-probe) and it keeps its molecular form even after low temperature calcination at $473 \mathrm{~K}$ as shown by TGA and XPS results.

The band observed at $2135 \mathrm{~cm}^{-1}$ on FTIR spectrum of $130 \mathrm{Pd} 2_{\mathrm{nw}}(0.5 \% \mathrm{Pd})$ (Fig. 3b) is characteristic of $\mathrm{CO}$ adsorption on partially oxidized Pd [49]. Nevertheless, this Pd is much less oxidized than the species observed by XPS which are closer to $\mathrm{adO}_{2}$ species $\left(\mathrm{Pd}^{\mathrm{IV}}\right)$. During thermal pretreatment at $723 \mathrm{~K}$ before IR analysis, $\mathrm{Pd}\left(\mathrm{NO}_{2}\right)_{4}{ }^{2-}$ could be partially decomposed and reduced (by $\mathrm{NO}_{2}{ }^{-}$ligand to form $\mathrm{NO}_{3}{ }^{-}$) on alumina surface (in agreement with ATG results) leading to formation of $\mathrm{Pd}^{\circ}$ particles. The difference with XPS results can be due to the low temperature calcination in this case $(473 \mathrm{~K})$ being not high enough to decompose the palladium nitrite complex.

We have seen that on increasing the amount of $\mathrm{Pd}$, the $\mathrm{Pd}\left(\mathrm{NO}_{2}\right)_{4}{ }^{2-}$ complexes interact with different sites, initially the more energetic ones (strong and medium Lewis acid site) and after saturation with the less energetic CUS Lewis sites. Thus, this result may be correlated with the evolution of electronic properties, followed by XPS and FTIR of adsorbed CO, with particle density, considering that different interactions may be created when the Pd complex interacts with different types of surface sites. Increasing particle density tends to increase the fraction of Pd in interaction with less energetic sites, leading to a decrease of the overall metal-support interactions when Pd loading or particle density increase. This low metal-support interaction is also consistent with EXAFS results showing only $\mathrm{Pd}-\mathrm{Pd}$ bonds and no $\mathrm{Pd}-\mathrm{O}_{\text {support }}$ bonds. Moreover, one must keep in mind that these metal-support interactions are often generated during high temperature post treatment absent in this type of synthesis and as it is the case for $\mathrm{Pd}[\mathrm{acac}]$ catalysts preparation.

Another interpretation may be proposed by a direct interparticle interaction as recently proposed by Rostovshchikova et al. [69]. Indeed even if the calculation of the inter-particle distance, from BET surface area value, seems to give rather high values (ranging from 4 to $10 \mathrm{~nm}$ ), one should consider the real topology of the porous support, including three-dimensional topology which may lead to real inter-particle distances much lower that theoretical ones.

\section{Conclusion}

Highly dispersed $\mathrm{Pd}^{\circ}$ particles supported on alumina were prepared using a strongly stabilized complex in aqueous phase. These three-dimensional clusters with low metalsupport interactions exhibit original electronic properties compared to more classical highly dispersed particles prepared via acetylacetonate precursors. Moreover, keeping constant the particle size and increasing the amount of palladium, which means increasing in parallel the particle surface density, large variations of the electronic properties of the very small particles prepared in such a way were observed. A decrease of the binding energy of $\mathrm{Pd}_{3 \mathrm{~d} 5 / 2}$ in parallel with the linearly adsorbed $\mathrm{CO}$ wavenumber is correlated with an increase of the particle surface density. This modification may be ascribed to interactions with different surface germination sites due to the progressive saturation of the Lewis acid unsaturated sites starting from the strong to the weak ones when increasing the particle surface density. The nature of the alumina support and its surface area does not affect the physico-chemical properties of the supported particles, in agreement with the principle of the synthesis which is to avoid strong metal-support interactions such as grafting used for example in the case of Pd acetylacetonate precursor. These results show that, at least for this type of synthesis, particle surface density should no longer be neglected for catalysts comparison.

\section{Acknowledgements}

Authors would like to thanks C. Legens (XPS), T. Armaroli (FTIR), F. Tihay (MET, HAADF), L. Sorbier (Castaing microprobe) of the Physics \& Analysis Division of IFP for characterization results, discussion and support for interpretations.

\section{References}

[1] Y.I. Yermakov, Catal. Rev. Sci. Eng. 13 (1) (1976) 77.

[2] Y.I. Yermakov, J. Mol. Catal. 21 (1983) 35.

[3] Y. Iwasawa, Catal. Today 18 (1993) 21.

[4] Y. Iwasawa, Adv. Catal. 35 (1987) 187.

[5] Y. Iwasawa, in: Y. Iwasawa (Ed.), Tailored Metal Catalysts, Riedel, Dordrecht, Holland, 1986.

[6] Y.I. Yermakov, B.N. Kuznetsov, V.A. Zakharov, Stud. Surf. Sci. Catal. 8 (1981), Elsevier, Amsterdam.

[7] J.P. Candy, B. Didillon, E.L. Smith, T.M. Shay, J.M. Basset, J. Mol. Catal. 86 (1994) 179.

[8] J.P. Boitiaux, J. Cosyns, S. Vasudevan, Appl. Catal. 6 (1983) 41.

[9] J. Goetz, M.A. Volpe, A.M. Sica, C.E. Gigola, R. Touroude, J. Catal. 153 (1) (1995) 86.

[10] J.A.R. Van Veen, G. Jonkers, W.H. Hesselink, J. Chem. Soc., Faraday Trans. 185 (2) (1989) 389. 
[11] C. Louis, M. Che, in: G. Ertl, H. Knözinger, J. Weitkamp (Eds.), Handbook of Heterogeneous Catalysis, Wiley-VCH, Weinheim, 1997, p. 207.

[12] M. Ichikawa, Adv. Catal. 38 (1992) 283.

[13] M. Womes, T. Cholley, F. Le Peltier, S. Morin, B. Didillon, N. SzydlowskiSchildknecht, Appl. Catal. 283 (2005) 9.

[14] J.R. Anderson, Structure of Metallic Catalysts, Academic Press, London, 1975.

[15] M. Schreier, J.R. Regalbuto, J. Catal. 225 (2004) 190.

[16] M. Che, C.O. Bennett, Adv. Catal. 36 (1989) 55.

[17] B. Shelimov, J. Lehman, J.F. Lambert, M. Che, B. Didillon, Bull. Soc. Chim. Fr. 133 (1996) 617.

[18] A. Goguet, D. Schweich, J.P. Candy, J. Catal. 220 (2003) 280.

[19] M. Vaarkamp, J.T. Miller, F.S. Modica, D.C. Koningsberger, J. Catal. 163 (1996) 294.

[20] D.C. Koningsberger, M.K. Oudenhuijzen, J. de Graaf, J.A. van Bokhoven, D.E. Ramaker, J. Catal. 216 (2003) 178.

[21] A.Y. Stakheev, L.M. Kustov, Appl. Catal. 188 (1999) 3.

[22] R.A. Dalla Betta, M. Boudart, in: H. Hightower (Ed.), Proceedings of the 5th International Congress on Catalysis, North Holland, Amsterdam, 1973 , p. 1329.

[23] M. Boudart, G. Djega-Marriadassou, Kinetics of Heterogeneous Catalytic Reaction, Princeton University Press, Princeton, NJ, 1984.

[24] P. Gallezot, J. Datka, J. Massadier, M. Primet, B. Imelik, in: G.C. Bond, et al. (Eds.), Proceedings of the 6th International Congress on Catalysis, The Chemical Society, London, 1977, p. 696.

[25] W.M.H. Sachtler, Z.C. Zhang, Adv. Catal. 39 (1993) 383.

[26] B. Ealet, E. Gillet, Surf. Sci. 367 (1996) 221.

[27] J.C. Bertolini, P. Delichère, B.C. Khandra, J. Massardier, C. Noupa, B. Tardy, Catal. Lett. 6 (1990) 215.

[28] J.R. Katzer, G.C.A. Smith, J.H.C. van Hoof, J. Catal. 59 (1979) 278.

[29] R. Bouwman, P. Biloen, J. Catal. 48 (1977) 209.

[30] Z. Karpinski, Adv. Catal. 37 (1990) 45.

[31] J. Jellinek, P.H. Acioli, J. Phys. Chem. A 106 (2002) 10919.

[32] U. Heiz, W.D. Schneider, J. Phys. D33 (2000) R85.

[33] U. Heiz, A. Sanchez, S. Abbet, W.D. Schneider, JACS 121 (1999) 3214.

[34] E.K. Parks, B.H. Weiller, P.S. Bechthold, W.F. Hoffman, G.C. Nieman, L.G. Pobo, S.J. Riley, J. Chem. Phys. 88 (1988) 1622.

[35] K. Judai, S. Abbet, A.S. Wörz, U. Heiz, C.R. Henry, JACS 126 (2004) 2732.

[36] A.M. Argo, J.F. Odzak, B.C. Gates, JACS 125 (2003) 7107.

[37] R.J. Matyi, L.H. Schwartz, J.B. Butt, Catal. Rev. Sci. Eng. 29 (1) (1987) 41.

[38] J.H. Sinfelt, G.H. Via, F.M. Lytle, Catal. Rev. Sci. Eng. 26 (1984) 81.

[39] D.E. Sayers, B.A. Bruncker, in: D.C. Koningsberger, R. Prins (Eds.), Xray Absorption: Principles, Applications, Techniques of EXAFS, Sexafs and Xanes, John Wiley \& Sons, 1998, p. 211.
[40] A. Michalowicz, G. Vlaic, Multiple solutions in data fitting: a trap in Exafs structural analysis and some ideas to avoid it, J. Synch. Rad. 5 (1998) 1317.

[41] L.I. Elding, L. Olsson, J. Phys. Chem. 82 (1) (1978) 69.

[42] A. Rakai, D. Tessier, F. Bozon-Verduraz, New J. Chem. 16 (1992) 869.

[43] N.M. Sinitsyn, T.M. Buslaeva, P.I. Ukraintseva, L.V. Samarova, Russ. J. Inorg. Chem. 30 (3) (1985) 407.

[44] N.M. Sinitsyn, T.M. Buslaeva, V.I. Efanov, I.A. Khartonik, Russ. J. Inorg. Chem. 33 (6) (1988) 833.

[45] N.N. Chalisova, O.G. Leonava, D.I. Kochubei, M.I. Yusko, Russ. J. Inorg. Chem. 33 (2) (1988) 227.

[46] H. Knözinger, P. Ratnasamy, Catal. Rev. Sci. Eng. 17 (1978) 31.

[47] C. Morterra, G. Magnacca, Catal. Today 27 (3-4) (1996) 497-532.

[48] T. Armaroli, A.A. Quoineaud, B. Rebours, R. Revel, OGST, in press.

[49] K.I. Hadjiivanov, G.N. Vayssilov, Adv. Catal. 47 (2002) 308.

[50] T.V. Bychkova, E.V. Lunina, A.K. Selivanovskii, E.A. Nikiel, T.Y. Smagina, B.V. Strakhov, Zh. Fiz. Khim. 55 (1981) 2599.

[51] T.V. Bychkova, E.V. Lunina, A.K. Selivanovskii, B.V. Strakhov, Zh. Fiz. Khim. 55 (1981) 2697.

[52] K. Klementiev, A. Stakheev, O. Tkachenko, N. Tolkachev, W. Grünert, http://www-hasylab.desy.de/science/annual_reports/2002_report/part1/ contrib/41/7389.pdf.

[53] M. Borowski, J. Phys. IV (1997) C2-C259.

[54] A.I. Frenkel, C.W. Hills, R.G. Nuzzo, J. Phys. Chem. B 105 (51) (2001) 12689.

[55] J.R. Katzer, G.C.A. Smith, J.H.C. van Hoof, J. Catal. 59 (1979) 278

[56] C.R. Henry, Surf. Sci. Rep. 31 (1998) 23-325.

[57] S. Kohiki, S. Ikeda, Phys. Rev. B 34 (6) (1986) 3786.

[58] L. Guczi, G. Petö, A. Beck, Z. Paszti, Top. Catal. 29 (3-4) (2004) 129.

[59] L.V. Nosova, M.V. Stenin, Yu.N. Nogin, Yu.A. Ryndin, Appl. Catal. A: Gen. 55 (1992) 43.

[60] D. Tessier, A. Rakai, F. Bozon-Verduraz, Bull. Soc. Chim. Fr. (1996) 63.

[61] C. Binet, A. Jadi, J.C. Lavalley, J. Chim. Phys. 86 (1989) 451.

[62] J.S. Bradley, J.M. Millar, E.W. Hill, S. Behal, J. Catal. 129 (1991) 333.

[63] E. Blyholder, J. Phys. Chem. 68 (10) (1964) 2772.

[64] J. Goetz, M.A. Volpe, A.M. Sica, C.E. Gigola, R. Touroude, J. Catal. 153 (1995) 86.

[65] M. Delage, B. Didillon, Y. Huiban, J. Lynch, D. Uzio, Stud. Surf. Sci. Catal. 130B (2000) 1019.

[66] H.J. Freund, Surf. Sci. 500 (2002) 271.

[67] L. Gmelin, in: Berlin, R.J. Meyer (Eds.), Gmelin Handbook of Inorganic Chemistry (Pd supplement volume B2), 1989.

[68] Th. Pagès, E. Merlen, B. Didillon, D. Uzio, Stud. Surf. Sci. Catal. 118 (1998) 41.

[69] T.N. Rostovshchikova, V.V. Smirnov, S.A. Gurevich, V.M. Kozhevin, D.A. Yavsin, S.M. Nevskaya, S.A. Nikolaev, E.S. Lokteva, Catal. Today 105 (2005) 344. 